\title{
Bonding and elastic properties of amorphous $\mathrm{AlYB}_{\mathbf{1 4}}$
}

\author{
Denis Music a,*, Felix Hensling a, Tomas Pazur ${ }^{a}$, Jozef Bednarcik ${ }^{b}$, Marcus Hans ${ }^{a}$, \\ Volker Schnabel $^{\mathrm{a}}$, Carolin Hostert ${ }^{\mathrm{a}}$, Jochen M. Schneider ${ }^{\mathrm{a}}$ \\ a Materials Chemistry, RWTH Aachen University, Kopernikusstr. 10, D-52074 Aachen, Germany \\ ${ }^{\mathrm{b}}$ Deutsches Elektronen Synchrotron, DESY, Notkestr. 85, D-22607 Hamburg, Germany
}

\section{A R T I C L E I N F O}

\section{Article history:}

Received 4 April 2013

Received in revised form

28 May 2013

Accepted 17 June 2013

by J. R. Chelikowsky

Available online 28 June 2013

Keywords:

A. Ceramics

C. Amorphous

D. Elasticity

D. Electronic band structure

\begin{abstract}
A B S T R A C T
We have studied the bonding and elastic properties of amorphous AlYB $_{14}$ using theoretical and experimental means. Based on pair distribution functions and Voronoi tessellation, the icosahedral bonding is expected. A rather large Young's modulus of $365 \mathrm{GPa}$ is predicted for amorphous $\mathrm{AlYB}_{14}$. To verify these predictions, we have measured density, pair distribution functions, binding energy and elastic properties of Al-Y-B thin films synthesized by magnetron sputtering. The calculated and measured densities are with a deviation of $3.5 \%$ in good agreement. The measured binding energy and pair distribution functions are also consistent with icosahedral bonding. The measured Young's modulus is $305 \pm 19 \mathrm{GPa}$, which is $16 \%$ smaller than the theoretical value and hence in good agreement. Overall consistency between theory and experiments was obtained indicating that the computational strategy employed here is useful to describe correlations between bonding, elasticity, density as well as (chemical) short range order and may hence enable future knowledge-based design of these ternary borides which show great potential for surface protection applications.
\end{abstract}

(c) 2013 Elsevier Ltd. All rights reserved.

\section{Introduction}

AlYB $_{14}$ (space group Imma) belongs to a group of boron-rich solids with fascinating properties. Many compounds are known, such as $\mathrm{AlMgB}_{14}, \mathrm{AlNaB}_{14}, \mathrm{AlLiB}_{14}, \mathrm{AlYB}_{14}, \mathrm{AlTbB}_{14}, \mathrm{AlDyB}_{14}, \mathrm{AlHoB}_{14}$, $\mathrm{AlErB}_{14}, \mathrm{AlYbB}_{14}$ and $\mathrm{AlLuB}_{14}$ [1-5]. Bulk modulus of $\mathrm{AlMgB}_{14}$ was measured to be in the range of 196-264 GPa [6]. Kölpin et al. performed $a b$ initio calculations on $X_{M g B}(X=\mathrm{Al}, \mathrm{C}, \mathrm{Si}, \mathrm{Ge}, \mathrm{Mg}, \mathrm{Sc}$, Ti, V, Zr, Hf, Nb, Ta) [7] as well as $\mathrm{Al}_{x} \mathrm{Y}_{y} \mathrm{~B}_{14}(x, y=0.25,0.5,0.75$, 1.00) [8] and reported bulk moduli in the range from 196 to $228 \mathrm{GPa}$. Similar values were calculated for $\mathrm{AlMgB}_{14}$ and $(\mathrm{Al}, \mathrm{Si})$ $\mathrm{MgB}_{14}[9,10]$. Hardness values in the range of $30 \mathrm{GPa}$ were measured for $\mathrm{AlLiB}_{14}$ [4]. With the addition of $\mathrm{TiB}_{2}$ to $\mathrm{AlMgB}_{14}$ hardness values up to $46 \mathrm{GPa}$ were reported [11]. These ternary borides are semimetallic (band gap $0.3 \mathrm{eV}$ for $\mathrm{ErAlB}_{14}$ [12]), implying good electrical conductivity and large Seebeck coefficient $\left(6500 \mu \mathrm{V} \mathrm{K}^{-1}\right.$ for $\mathrm{MgAlB}_{14}$ [12]), which gives rise to a potential application in thermoelectric devices. Furthermore, they may possess considerable tolerance against radiation damage [13]. All reviewed data refer to crystalline samples.

Many properties of these ternary borides remain unexplored, leaving out possible applications. To the best of our knowledge, no physical properties of $\mathrm{AlYB}_{14}$ have ever been measured. Generally,

\footnotetext{
* Corresponding author. Tel.: +49 241 8025892; fax: +49 2418022295.

E-mail address: music@mch.rwth-aachen.de (D. Music).
}

this may be due to high bulk growth temperature for these borides exceeding $1400{ }^{\circ} \mathrm{C}$ [4]. Corresponding thin films are thus amorphous [14]. Characterization of amorphous thin films is challenging, but in general amorphous compounds can have enhanced physical and chemical properties. For instance, metallic glasses have superior mechanical properties compared to corresponding crystals [15,16], amorphous pharmaceuticals are remarkably more soluble than their crystalline counterparts [17] and Ge-Sb-Te alloys are used for optical and electrical data storage based on amorphous-to-crystalline transitions $[18,19]$.

In this work, we explore the bonding and elastic properties of amorphous $\mathrm{AlYB}_{14}$ using theoretical and experimental methods. Based on $a b$ initio data, stiff icosahedral bonding is expected. To verify these predictions, we measure density, pair distribution functions (PDFs), binding energy and elastic properties of Al-Y-B thin films synthesized by magnetron sputtering. Consistency is obtained between the theoretical and experimental data.

\section{Theoretical methods}

Ab initio molecular dynamics (MD) simulations were performed using the OpenMX code [20], based on the density functional theory [21] and basis functions in the form of linear combination of localized pseudoatomic orbitals [22]. The electronic potentials were fully relativistic with partial core corrections $[23,24]$ and the generalized gradient approximation was applied [25]. The basis 
functions used were generated by a confinement scheme $[22,26]$ and specified as follows: Al6.0-s2p2, Y6.5-s3p2d1 and B4.5-s2p2. The first symbol designates the chemical name, followed by the cutoff radius (Bohr radius units) in the confinement scheme and the last set of symbols defines primitive orbitals applied. The energy cutoff $(150 \mathrm{Ry})$ and $k$-point grid $(1 \times 1 \times 1)$ within the real space grid technique [27] were adjusted to reach the accuracy of $10^{-6} \mathrm{H}$ /atom. In these simulations, the MD time step was $1.0 \mathrm{fs}$. As $\mathrm{AlYB}_{14}$ bulk samples are always substoichiometric with respect to metals reaching the nominal composition $\mathrm{Al}_{0.71} \mathrm{Y}_{0.62} \mathrm{~B}_{14}$ [5], we performed the $a b$ initio $\mathrm{MD}$ simulations with $\mathrm{Al}_{0.75} \mathrm{Y}_{0.75} \mathrm{~B}_{14}$. To create an amorphous $\mathrm{Al}_{0.75} \mathrm{Y}_{0.75} \mathrm{~B}_{14}$ configuration, 124 atoms were placed on the positions based on isostructural crystalline $\mathrm{AlNaB}_{14}$ [3]. This $\mathrm{Al}_{0.75} \mathrm{Y}_{0.75} \mathrm{~B}_{14}$ configuration was run in a cubic supercell at the temperature of $3000 \mathrm{~K}$ within a canonical ensemble for $500 \mathrm{fs}$, by scaling the velocities. It was then quenched to $0 \mathrm{~K}$ and fully relaxed. This procedure allows for creation of a representative amorphous configuration [28-30]. The density was calculated from the energy-volume data. The bulk modulus was obtained using the Birch-Murnaghan equation of state [31]. All elastic constants within the cubic symmetry were calculated by distorting the supercell and fitting with a second-order polynomial function [32].

To process and visualize the OpenMX data, we developed a scientific visualization tool called atomic structure analysis package (ASAP). The ASAP runs under Java and directly uses the input from the OpenMX code. It allows for the analysis of bond lengths and angles, total energy, diffusion and Voronoi polyhedra both statically as well as dynamically. The diffusion analysis is carried out by applying Einstein's equation [33]. Voronoi polyhedra and atoms during the visualization with ASAP run can be traced. The Voronoi tessellation includes the calculation of coordination numbers, Voronoi index and size of Voronoi polyhedra [34,35].

\section{Experimental methods}

Al-Y-B thin films were synthesized in an ultra-high vacuum system with a base pressure of $4 \times 10^{-5}$ Pa by magnetron sputtering with a power density of $5.1 \mathrm{~W} / \mathrm{cm}^{2}$ for a stoichiometric $\mathrm{AlYB}_{14}$ target (purity $99.9 \%$, pulsed DC, $100 \mathrm{kHz}$ ). This compound target was mounted on a magnetron in an off-axis configuration with the substrate-to-source distance of $10 \mathrm{~cm}$ and the angle of 19 between the substrate and plasma source normal. The $\mathrm{Si}(100)$ substrates were rotated and kept at room temperature during synthesis. Ar (99.9999\%) was used as a sputtering gas with a total pressure of $0.4 \mathrm{~Pa}$.

The Al-Y-B thin film composition was determined by energy dispersive $\mathrm{X}$-ray analysis with an EDAX Genesis 2000 analyzer. The stoichiometric $\mathrm{AlYB}_{14}$ compound target was used as a standard. The chemical bonding was probed by x-ray photoelectron spectroscopy (XPS) in a JAMP-9500F system (JEOL) with a $K_{\alpha} \mathrm{Mg}$ x-ray source (energy $1253.6 \mathrm{eV}$ ) and a hemispherical electron energy analyzer with a pass energy of $20 \mathrm{eV}$. The energy calibration was carried out against the $\mathrm{Au} 4 f_{7 / 5}$ line $(84.0 \mathrm{eV})$. Al-Y-B thin films were etched for $2 \mathrm{~min}$ with $2 \mathrm{keV} \mathrm{Ar}^{+}$ions to remove surface contaminations (no chemical shifts were induced). The structural analysis was conducted by X-ray diffraction (XRD) in a Bruker AXS D8 Discover General Area Detection Diffraction System (GADDS) with $\mathrm{Cu} K_{\alpha}$ radiation as well as using high energy photons available at the P02.1 undulator beamline of the PETRA III electron storage ring (Hamburg, Germany). For the GADDS measurements, a collimator with a diameter of $0.5 \mathrm{~mm}$ and an incidence angle of $15^{\circ}$ were used. A current setting of $40 \mathrm{~mA}$ and a generator voltage of $40 \mathrm{kV}$ were applied. For the XRD measurements at P02.1 beamline, five independent scans at room temperature were acquired in transmission mode with $59.8 \mathrm{keV}$ (wavelength $0.02073 \mathrm{~nm}$ ), $30 \mathrm{~s}$ illumination time, a fast image plate detector and a detector-to-sample distance of $51.3 \mathrm{~cm}$. Two-dimensional XRD patterns were integrated and PDFs were obtained. Details can be found elsewhere [30]. Furthermore, the film density was obtained from the mass difference of the substrate before and after deposition as well as the thickness measurement obtained by field emission secondary electron microscopy in the JAMP-9500F system (JEOL). The working distance of $\sim 25 \mathrm{~mm}$ and the accelerating voltage of $7 \mathrm{kV}$ were applied. Nanoindentation experiments were performed in a Hysitron TriboIndenter coupled with an atomic force microscope. A Berkovich diamond tip, with the tip area function obtained from calibration on fused silica, was applied for the measurements using the Oliver and Pharr method [36]. The specimen was characterized by 16 indents having the maximum penetration $<10 \%$ of the film thickness.

\section{Results and discussion}

The obtained $\mathrm{Al}_{0.75} \mathrm{Y}_{0.75} \mathrm{~B}_{14}$ configuration appears amorphous as it can be seen in Fig. 1. To verify this, we perform the structural analysis in terms of PDFs and Voronoi tessellation using the ASAP code. Fig. 2 shows the calculated and measured PDFs for amorphous $\mathrm{Al}_{0.75} \mathrm{Y}_{0.75} \mathrm{~B}_{14}$. Consistency between the theory and experiment is achieved considering the major features of the PDFs. Some minor deviations between PDFs may at least in part be due to the fact that the reciprocal lattice vector dependence of the $\mathrm{x}$-ray atomic scattering factors (only atomic numbers were considered) were neglected during the calculation of the theoretical PDF from the configuration given in Fig. 1. It is clear that the structure is amorphous due to a broad continuous distribution obtained. The first pair distribution peak is positioned at $1.70 \AA$ and it may be related to $\mathrm{B}-\mathrm{B}$ bonding. This is consistent with icosahedral bonding, since in crystalline $\alpha-\mathrm{B}, \mathrm{B}_{4} \mathrm{C}, \mathrm{B}_{6} \mathrm{~N}, \mathrm{~B}_{6} \mathrm{O}, \mathrm{B}_{6} \mathrm{P}$ and $\mathrm{B}_{6} \mathrm{As}$ the $\mathrm{B}-\mathrm{B}$ bond length is in the range from 1.68 to $1.88 \AA$ [37]. This is also consistent with amorphous $\mathrm{B}_{6} \mathrm{O}$ based solids [29]. Based on the Voronoi tessellation analysis of $\mathrm{Al}_{0.75} \mathrm{Y}_{0.75} \mathrm{~B}_{14}$, the most common coordination of $\mathrm{B}$ is 8 . This large coordination number is found in bulk metallic glasses, such as $\mathrm{Zr}_{40} \mathrm{Fe}_{40} \mathrm{~B}_{20}$ [38], where icosahedrallike coordination exists. Hence, it appears based on both analysis approaches that the icosahedral bonding is the dominating bonding type. This is also consistent with bulk AlYB $_{14}$ [5].

To further verify the predicted structural and bonding data, we measure density and XPS chemical shifts of the Al-Y-B thin film synthesized by magnetron sputtering. $\mathrm{X}$-ray amorphous thin film

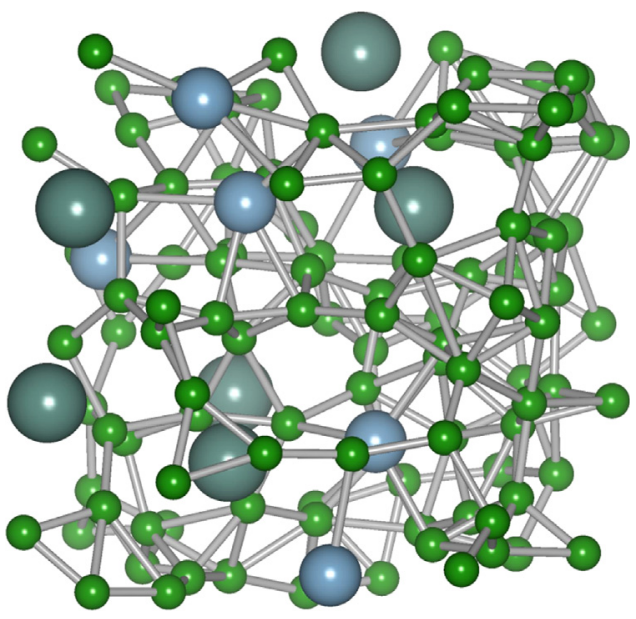

Fig. 1. (Color online) Structure of $\mathrm{Al}_{0.75} \mathrm{Y}_{0.75} \mathrm{~B}_{14}$ containing 124 atoms. Large, medium and small spheres designate $\mathrm{Y}, \mathrm{Al}$ and $\mathrm{B}$, respectively. 


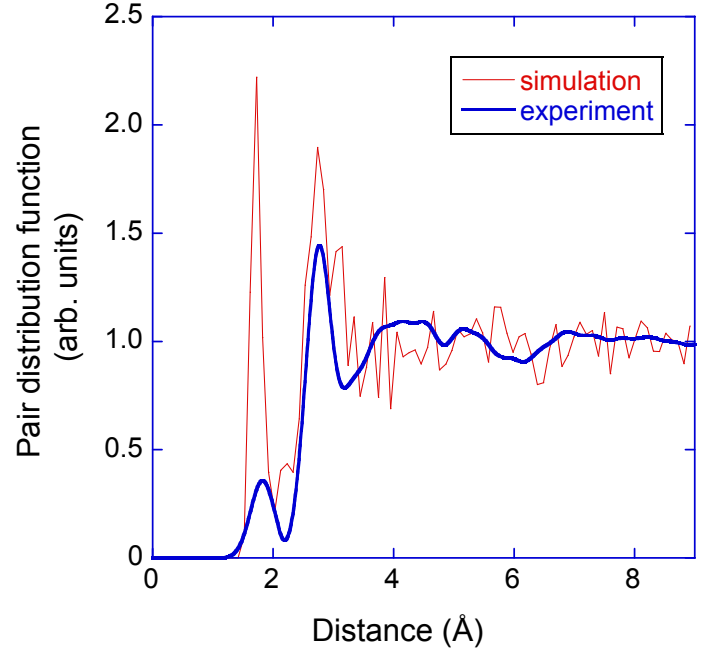

Fig. 2. (Color online) Comparison of experimental total pair distribution function and the one obtained by analyzing $3 \mathrm{D}$ structural model of $\mathrm{Al}_{0.75} \mathrm{Y}_{0.75} \mathrm{~B}_{14}$ presented in Fig. 1.

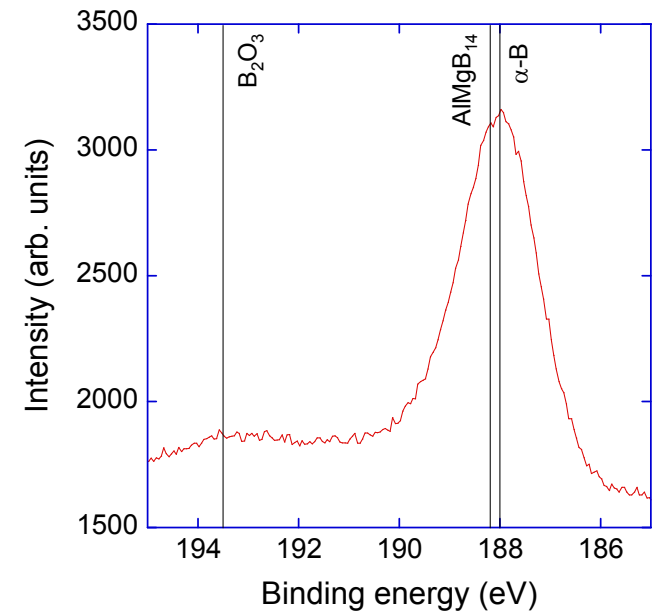

Fig. 3. (Color online) X-ray photoelectron spectroscopy data for B 1s peak for X-ray amorphous $\mathrm{Al}_{0.84} \mathrm{Y}_{0.75} \mathrm{~B}_{14}$ thin film.

exhibits the chemical composition $\mathrm{Al}_{0.84} \mathrm{Y}_{0.75} \mathrm{~B}_{14}$, which is rather close to the composition used in ab initio MD simulations. The calculated and measured density is 3.04 and $3.15 \pm 0.06 \mathrm{~g} / \mathrm{cm}^{3}$, respectively. The deviation is $3.5 \%$, which is within the acceptable precision level. According to our bonding analysis presented above, the dominating bonding is of the icosahedral nature. This can be probed by XPS. Fig. 3 shows the $\mathrm{B} 1 \mathrm{~s}$ peak for $\mathrm{Al}_{0.84} \mathrm{Y}_{0.75} \mathrm{~B}_{14}$ thin film. The observed binding energy is consistent with icosahedral bonding in $\alpha$-B [39] and $\mathrm{AlMgB}_{14}$ [40], as indicated by the vertical solid lines in Fig. 3. $\mathrm{B}_{2} \mathrm{O}_{3}$ bonding is present to lesser extent most likely only due to surface contamination.

After analyzing the bonding nature of amorphous $\mathrm{Al}_{0.75} \mathrm{Y}_{0.75} \mathrm{~B}_{14}$, we turn our attention to the elastic properties. The calculated bulk modulus is $195 \mathrm{GPa}$ and all elastic constants are as follows: $C_{11}=$ $399 \mathrm{GPa}, C_{12}=93 \mathrm{GPa}$ and $C_{44}=154 \mathrm{GPa}$. As the bulk modulus for crystalline $\mathrm{Al}_{x} \mathrm{Y}_{y} \mathrm{~B}_{14}(x, y=0.25,0.5,0.75,1.00)$ was reported to be in the range 196-220 GPa [8], the obtained value is relatively large for an amorphous counterpart, but acceptable. We can also estimate the degree of isotropy and hence assess self-consistently if our supercell is sufficiently large to describe this amorphous solid properly. It can thus trivially be obtained that $1 / 2\left(C_{11}-C_{12}\right)=153 \mathrm{GPa}$. In a perfectly isotropic solid, this should be equal to $C_{44}$ [41]. In our case, there is only $1 \mathrm{GPa}$ difference, signifying that our model is truly isotropic and

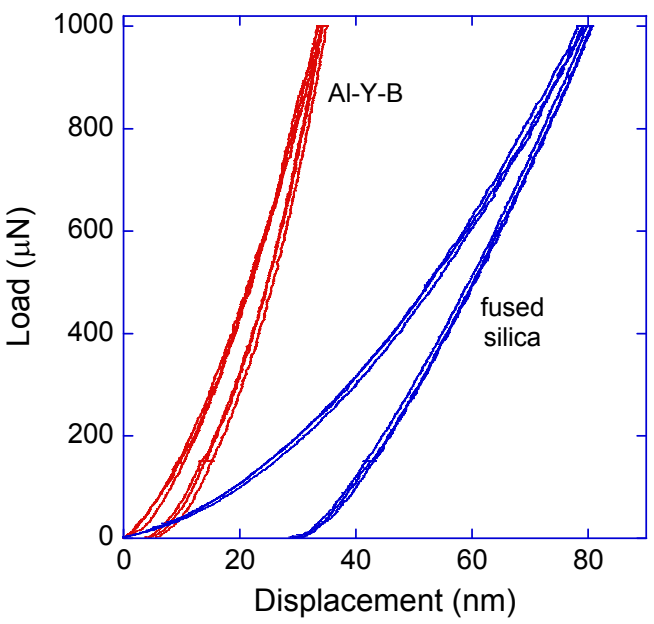

Fig. 4. (Color online) Nanoindentation data for $\mathrm{x}$-ray amorphous $\mathrm{Al}_{0.84} \mathrm{Y}_{0.75} \mathrm{~B}_{14}$ thin film (three curves) and fused silica standard (three curves).

can be used to describe the short-range order and elastic properties of this ternary boride. Due to this isotropy, both Voigt and Reuss approximations [41] give identical values for Young's modulus and Poisson's ratio of $365 \mathrm{GPa}$ and 0.19 , respectively.

To verify the predicted elasticity data, we carry out nanoindentation measurements of the X-ray amorphous Al-Y-B thin film. Fig. 4 shows examples of load-displacement curves for the $\mathrm{Al}_{0.84} \mathrm{Y}_{0.75} \mathrm{~B}_{14}$ thin film and a fused silica standard. It is apparent that the maximum penetration in the fused silica is larger than in the $\mathrm{Al}_{0.84} \mathrm{Y}_{0.75} \mathrm{~B}_{14}$ thin film and that the slope of the unloading curve for the $\mathrm{Al}_{0.84} \mathrm{Y}_{0.75} \mathrm{~B}_{14}$ thin film is noticeably steeper. Furthermore, there are no pop-in events, which are not expected for amorphous samples. From these nanoindentation data together with the calculated Poisson's ratio of 0.19, Young's modulus can be obtained. The measured value for Young's modulus is thus $305 \pm 19 \mathrm{GPa}$. This deviates $16 \%$ with respect to the calculated value. With the exchange-correlation functional approximation used, this deviation is acceptable [42]. It should be noted that the obtained value for Young's modulus is rather large for an amorphous thin film. For instance, amorphous $\mathrm{Al}_{2} \mathrm{O}_{3}$ [43], $\mathrm{B}_{6} \mathrm{O}$ [44] and $\mathrm{Si}_{3} \mathrm{~N}_{4}$ [45] thin films exhibit Young's modulus of 177, 248 and $241 \mathrm{GPa}$, respectively.

\section{Conclusion}

We have investigated the bonding and elastic properties of amorphous $\mathrm{AlYB}_{14}$ using theoretical and experimental methods. Based on PDFs and Voronoi tessellation analyses of amorphous $\mathrm{Al}_{0.75} \mathrm{Y}_{0.75} \mathrm{~B}_{14}$, the most dominating bonding is expected to be icosahedral in nature. The calculated Young's modulus of amorphous $\mathrm{Al}_{0.75} \mathrm{Y}_{0.75} \mathrm{~B}_{14}$ is $365 \mathrm{GPa}$. To verify these theoretical data, we have measured density, PDFs, XPS chemical shifts and elastic properties of Al-Y-B thin films synthesized by pulsed DC magnetron sputtering. The as-grown $\mathrm{X}$-ray amorphous thin film exhibits the chemical composition $\mathrm{Al}_{0.84} \mathrm{Y}_{0.75} \mathrm{~B}_{14}$. The calculated and measured density is 3.04 and $3.15 \pm 0.06 \mathrm{~g} / \mathrm{cm}^{3}$, respectively. The deviation is $3.5 \%$, which is within the acceptable precision level. The measured binding energy and PDFs are consistent with the icosahedral bonding prediction. The measured value for Young's modulus is $305 \pm 19 \mathrm{GPa}$, which deviates by $16 \%$ with respect to the calculated value. Thus, consistency between theoretical and experimental data was obtained. Our computational model is beneficial to describe correlations between bonding, density, short-range order and elasticity and hence provides a solid basis for future knowledge-based design of amorphous solids. 


\section{Acknowledgments}

The authors thank F. Nahif, RWTH Aachen University, for useful discussions. This work was supported by the Deutsche Forschungsgemeinschaft within the Collaborative Research Center SFB-TR 87/1 Pulsed high power plasmas for the synthesis of nanostructured functional layers.

\section{References}

[1] V.I. Matkovich, J. Economy, Acta Cryst. B26 (1970) 616

[2] J.S. Peters, J.M. Hill, A.M. Russell, Scr. Mater. 54 (2006) 813.

[3] S. Okada, T. Tanaka, A. Sato, T. Shishido, K. Kudou, K. Nakajima, T. Lundström, J. Alloy Compd. 395 (2005) 231.

[4] I. Higashi, M. Kobayashi, S. Okada, K. Hamano, T. Lundström, J. Cryst. Growth 128 (1993) 1113.

[5] M.M. Korsukova, T. Lundström, L.-E. Tergenius, V.N. Gurin, J. Alloy Compd. 187 (1992) 39.

[6] D.V.S. Muthu, B. Chen, B.A. Cook, M.B. Kruger, High Pressure Res. 28 (2008) 63

[7] H. Kölpin, D. Music, G. Henkelman, J.M. Schneider, Phys. Rev. B 78 (2008) 054122.

[8] H. Kölpin, D. Music, G. Henkelman, J. Emmerlich, F. Munnik, J.M. Schneider, J. Phys.: Condens. Matter 21 (2009) 355006.

[9] Y. Lee, B.N. Harmon, J. Alloy Compd. 338 (2002) 242

[10] J.E. Lowther, Physica B 322 (2002) 173.

[11] B.A. Cook, J.L. Harringa, T.L. Lewis, A.M. Russell, Scr. Mater. 42 (2000) 597

[12] H. Werheit, U. Kuhlmann, G. Krach, I. Higashi, T. Lundström, Y. Lu, J. Alloy Compd. 202 (1993) 269.

[13] D. Emin, J. Solid State Chem. 179 (2006) 2791

[14] Y. Tian, A.F. Bastawros, C.C.H. Lo, A.P. Constant, A.M. Russell, B.A. Cook, Appl. Phys. Lett. 83 (2003) 2781.

[15] A. Inoue, B. Shen, H. Koshiba, H. Kato, A.R. Yavari, Nature Mater. 2 (2003) 661

[16] C. Hostert, D. Music, V. Kapaklis, B. Hjörvarsson, J.M. Schneider, Scr. Mater. 66 (2012) 765.

[17] B.C. Hancock, M. Parks, Pharm. Res. 17 (2000) 397.
[18] M. Wuttig, N. Yamada, Nature Mater. 6 (2007) 824.

[19] Z. Sun, S. Kyrsta, D. Music, R. Ahuja, J.M. Schneider, Solid State Commun. 143 (2007) 240

[20] T. Ozaki, H. Kino, Phys. Rev. B 72 (2005) 045121.

[21] P. Hohenberg, W. Kohn, Phys. Rev 136 (1964) B864.

[22] T. Ozaki, Phys. Rev. B 67 (2003) 155108.

[23] N. Troullier, J.L. Martins, Phys. Rev. B 43 (1991) 1993.

[24] P.E. Blöchl, Phys. Rev. B 41 (1990) 5414.

[25] J.P. Perdew, K. Burke, M. Ernzerhof, Phys. Rev. Lett. 77 (1996) 3865.

[26] T. Ozaki, H. Kino, Phys. Rev. B 69 (2004) 195113.

[27] J.M. Soler, E. Artacho, J.D. Gale, A. Garcia, J. Junquera, P. Ordejon, D. SanchezPortal, J. Phys.: Condens. Matter 14 (2002) 2745.

[28] X. Zhang, D.A. Drabold, Phys. Rev. Lett. 83 (1999) 5042.

[29] D. Music, J.M. Schneider, J. Phys.: Condens. Matter 20 (2008) 195203.

[30] C. Hostert, D. Music, J. Bednarcik, J. Keckes, V. Kapaklis, B. Hjörvarsson, J.M. Schneider, J. Phys.: Condens. Matter 23 (2011) 475401.

[31] F. Birch, J. Geophys. Res. 83 (1978) 1257.

[32] D. Music, T. Takahashi, L. Vitos, C. Asker, I.A. Abrikosov, J.M. Schneider, Appl. Phys. Lett. 91 (2007) 191904.

[33] A. Einstein, Ann. Phys. 17 (1905) 549

[34] B.J. Gellatly, J.L. Finney, J. Mol. Biol. 161 (1982) 305.

[35] M.G. Voronoi, J. Reine Angew. Math. 134 (1908) 198.

[36] W.C. Oliver, G.M. Pharr, J. Mater. Res. 7 (1992) 1564.

[37] X. Guo, J. He, Z. Liu, Y. Tian, J. Sun, H.-T. Wang, Phys. Rev. B 73 (2006) 104115.

[38] J. Park, Y. Shibutani, Mater. Trans. 47 (2006) 2904.

[39] M. Belyansky, M. Trenary, Surf. Sci, Spectra 3 (1995) 147.

[40] C. Higdon, B. Cook, J. Harringa, A. Russell, J. Goldsmith, J. Qu, P. Blau, Wear 271 (2011) 2111.

[41] M.J. Mehl, J.E. Osburn, D.A. Papaconstantopoulos, B.M. Klein, Phys. Rev. B 41 (1990) 10311.

[42] J. Paier, M. Marsman, K. Hummer, G. Kresse, I.C. Gerber, J.G. Ángyán, J. Chem. Phys. 124 (2006) 154709.

[43] J.M. Schneider, K. Larsson, J. Lu, E. Olsson, B. Hjövarsson, Appl. Phys. Lett. 80 (2002) 1144.

[44] D. Music, U. Kreissig, R. Mertens, J.M. Schneider, Phys. Lett. A 326 (2004) 473.

[45] Z.Q. Yao, P. Yang, N. Huang, H. Sun, G.J. Wan, Y.X. Leng, J. Wang, J.Y. Chen, Surf. Coat. Technol. 200 (2006) 4144. 